
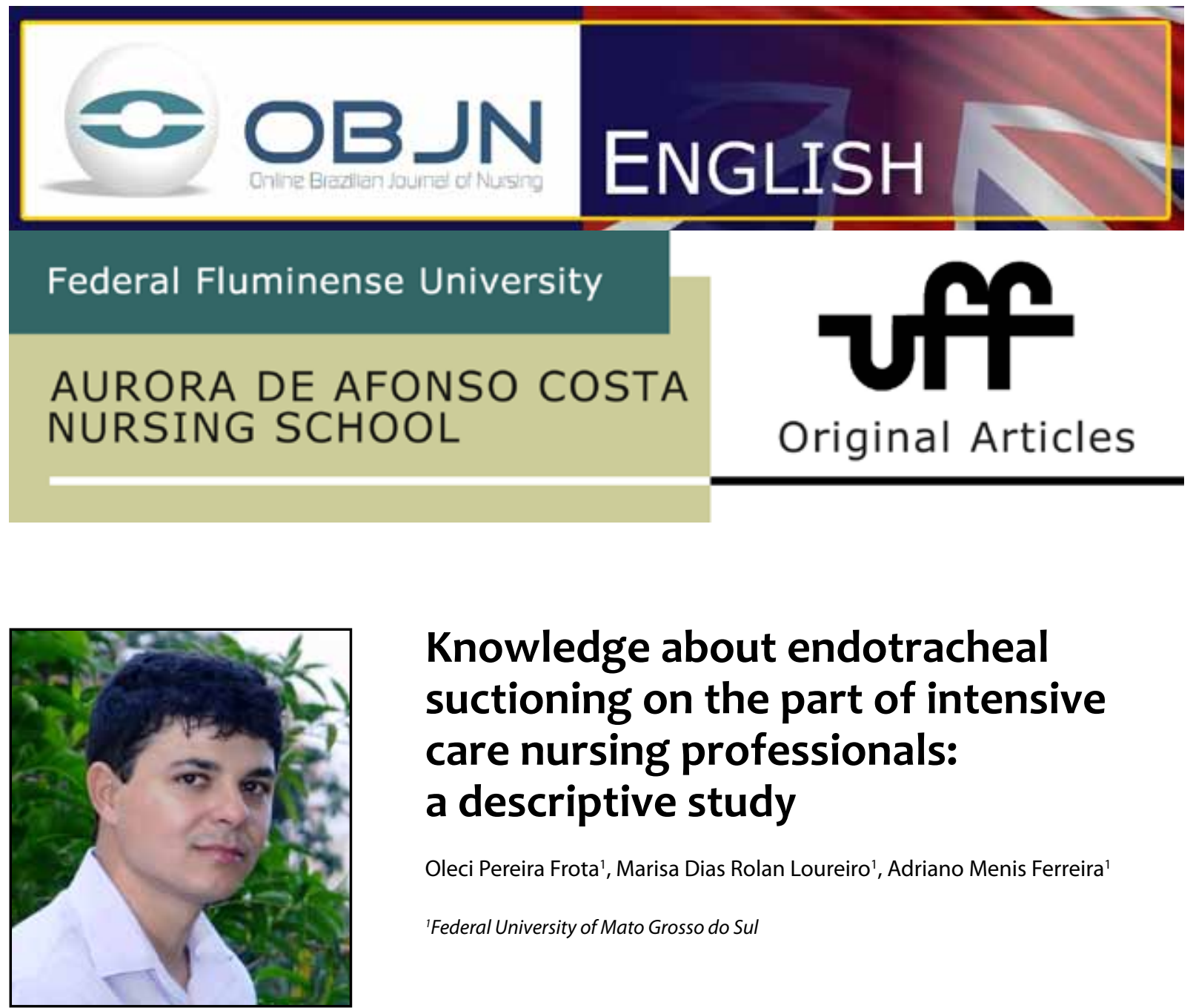

\title{
Knowledge about endotracheal suctioning on the part of intensive care nursing professionals: a descriptive study
}

Oleci Pereira Frota', Marisa Dias Rolan Loureiro', Adriano Menis Ferreira'

${ }^{1}$ Federal University of Mato Grosso do Sul

\section{ABSTRACT}

Aim: To evaluate the knowledge of nursing professionals in the Intensive Care Unit (ICU) about endotracheal aspiration (ETA) for open system.

Method:This an exploratory descriptive study in which a quantitative approach was used, performed in July 2011 in two ICUs of a large university hospital in Mato Grosso do Sul, Brazil. Data were collected through the means of a questionnaire. The sample consisted of 27 professionals of whom $51.9 \%$ were male.

Results: Globally, the knowledge of professionals was qualified as fair ( $73.2 \%$ correct), but worryingly, it was considered poor in five areas with differing results among the professional categories.

Discussion: Taking into account that incorrect knowledge generates inappropriate behavior, it is inferred that the practice of these subjects may compromise patient safety. Conclusion: The studied individuals showed knowledge deficits in some aspects of ETA, a fact that deserves investment regarding teaching and nursing.

Descriptors: Critical Care; Respiration, Artificial; Health Knowledge, Attitudes, Practice; Employee Performance Appraisal; Nursing, Team; Questionnaires. 


\section{INTRODUCTION}

One of the main goals of nursing is to provide evidence-based assistance in order to promote quality results for patients, families and the healthcare system. A procedure that deserves particular attention, given its direct relationship with the risk of infection, is the endotracheal aspiration (ETA) of intubated patients ${ }^{(1)}$.

The ETA is an essential component in airway management in patients on mechanical ventilation, being one of the most frequently performed invasive procedures in the Intensive Care Unit (ICU). Its main goal is to remove accumulated lung secretions in order to maintain the airway's permeability; provide adequate oxygenation; reduce the risk of ventilator-associated pneumonia (VAP) and prevent pulmonary consolidation and atelectasis ${ }^{(2)}$.

The procedure, however, is not free of risks and complications. Comorbidities such as cardiac and/or respiratory failure, hemodynamic instability, tracheobronchial injury and hypoxemia may be a result of the procedure, especially when performed incorrectly ${ }^{(3)}$. Therefore, it is imperative that this procedure is performed with professional competence, which means not only having the necessary skills, but also knowledge based on updated scientific evidence, guaranteeing efficiency and the safety of the patient ${ }^{(4)}$.

However, research has shown that nursing practitioners do not have sufficient knowledge of the current recommendations for ETA and, according to empirical evidence, the practice is often based on rituals and traditions ${ }^{(4.5)}$. Therefore, the question is: What is the knowledge of intensive care nursing professionals about the ETA procedure for open system in the light of the evidence? To answer this question we proposed this study, which aims to assess the knowledge of ICU nursing professionals relating to ETA for open systems.
The justification for this study represents a diagnostic step of paramount importance. We propose to investigate and critically evaluate the knowledge of professionals and identify the skills and difficulties involved, and, based on this data, develop operational measures that contribute to improvement in the quality of the services provided.

\section{METHOD}

This is an exploratory, descriptive study, whose data collection was conducted in July 2011 in two ICUs (general and cardiac). These ICUs provide care for adult patients at a large university hospital in Mato Grosso do Sul. The study was approved by the Ethics Committee on Human Research of the Federal University of Mato Grosso do Sul under the protocol No. 1949/2011.

The study included all the nursing professionals from the sectors investigated, so that the population was represented by 34 nurses, 18 working in the General ICU (two nurses, four nursing technicians and 12 nursing assistants) and 16 in the Cardiological ICU (two nurses, eight nursing technicians and six nursing assistants). However, we excluded the professionals who were on leave or vacation during the period of data collection and those who had less than one year of experience in the area of intensive care. Thus, the sample consisted of 27 professionals.

To meet the objective of this investigation we built a structured questionnaire composed of items relating to socio-demographic data and knowledge tests. The latter was aimed at identifying the level of knowledge of participants regarding the current recommended actions before, during and after the ETA technique for open systems, as well as prevention and infection control. 
In the final version, the component knowledge test consisted of 17 closed questions, as follows: 13 affirmations for which an " $\mathrm{X}$ " should be marked for one of the possible alternatives, true ( $\mathrm{T}$ ), false $(\mathrm{F})$ or I do not know (it was considered as a correct question the true statements answered as $\mathrm{T}$ or false answered as $\mathrm{F}$ ); three questions with multiple choice answers, in which case the assessed individual should mark an " $X$ " next to the answer(s) he/ she considered correct (with these questions, all options were correct and it was considered as correct when more than $50 \%$ of the alternatives were noted), and finally; a question that dealt with the opinions of the professionals regarding their difficulties in the management of artificial airways.

Note that this survey was based on the Guidelines $^{(6)}$ of the American Association for Respiratory Care (AARC) from 2010 and secondarily on other reference studies of the theme ${ }^{(1,7-9)}$, and these were used as parameters to define what was correct or incorrect. Data was collected during working hours, in a specific room. Consultation of bibliographies or co-workers was not allowed, and there was no time limit for completing the questionnaire in order to minimize the possibility of inducing participants to answer without first reading the questionnaire properly and reflecting. Prior to the delivery of the questionnaire, a quick explanation was given to the subjects involved, especially on the objectives of the study, its relevance and method of data collection. Particular emphasis was placed on the need for collaboration and voluntary participation. After reading, signing and returning the Terms of Consent, each participant received the questionnaire.

The data was collated using "Microsoft Office Excel" 2010 version and was analyzed using descriptive statistics. The methods of absolute and percentage distribution were employed, as well as the average and standard deviation for socio-demographics.

Moreover, based on an earlier similar stu$\mathrm{dy}^{(10)}$ that was initially based on other studies, we established a conceptual assignment) in wich we made a small semantic change) to investigate and classify the variables of knowledge. Furthermore, considering all the studies analyzed on evaluation of knowledge in different areas, there was no consensus for a cut-off point, therefore empiricism and what the authors considered a suitable level of knowledge prevailed.

Thus, we considered the following score diagram: equal or less than 59 points "poor knowledge"; 60-69 "weak"; 70-79 "average"; 8089 "good"; 90 to 99 "very good" and; 100 points was classified as "excellent knowledge".

\section{RESULTS}

Of the 27 (100\%) professionals investigated $11(40.8 \%)$ worked in the General ICU (two nurses, two nursing technicians and seven nursing assistants) and 16 (59.2\%) in the Cardiological ICU (two nurses, eight nursing technicians and six nursing assistants). Of this group, 14 (51.9\%) subjects were male. The average age was 40.6 years \pm 7 (24-55). The average time of experience in the position was 17.4 years \pm 7.6 (1-30) and the average time of exercise in an adult ICU was 10.2 years \pm 5.87 (1-23). Among nurses, three (75\%) were post graduates in lato sensus courses and; among those at professional training levels, 16 (70\%) had completed high school, six (26\%) were graduates (three in nursing) and one (4\%) was a post graduate in adult intensive care nursing.

The evaluation of the knowledge of these professionals regarding ETA is presented in Table 1. 
Table 1. Characterization of nursing professionals' responses $(n=27)$ about the ETA technique. Campo Grande/MS, Brazil, 2011

\begin{tabular}{|c|c|c|c|c|c|c|}
\hline \multirow{3}{*}{ Variables } & \multicolumn{6}{|c|}{ Answers } \\
\hline & \multicolumn{2}{|c|}{ Correct } & \multicolumn{2}{|c|}{ Incorrect } & \multicolumn{2}{|c|}{ Does not know } \\
\hline & $\mathbf{n}$ & $\%$ & $\mathbf{n}$ & $\%$ & $\mathbf{N}$ & $\%$ \\
\hline \multicolumn{7}{|l|}{ Before ETA } \\
\hline Explanation of the procedure to the patient & 25 & 92,6 & 1 & 3,7 & 1 & 3,7 \\
\hline Interruption of enteral diet & 23 & 85,2 & 3 & 11,1 & 1 & 3,7 \\
\hline Pre-oxygenation in order to prevent hypoxemia & 17 & 63 & 3 & 11,1 & 7 & 25,9 \\
\hline Main clinical situations that indicate the ETA & 26 & 96,3 & 1 & 3,7 & 0 & 0 \\
\hline Routine AET (pre-set times) or only when needed & 25 & 92,6 & 1 & 3,7 & 1 & 3,7 \\
\hline \multicolumn{7}{|l|}{ During ETA } \\
\hline Routine instillation of SF $0.9 \%$ in the TET * & 12 & 44,5 & 10 & 37 & 5 & 18,5 \\
\hline Use of suction catheter of appropriate diameter & 16 & 59,2 & 0 & 0 & 11 & 40,8 \\
\hline Maximum suction time (open vacuum) & 9 & 33,3 & 11 & 40,8 & 7 & 25,9 \\
\hline Monitoring of pulse oximetry & 26 & 96,3 & 1 & 3,7 & 0 & 0 \\
\hline $\begin{array}{l}\text { Procedure to insert the suction catheter in TET * (open or closed } \\
\text { vacuum) }\end{array}$ & 25 & 92,6 & 2 & 7,4 & 0 & 0 \\
\hline \multicolumn{7}{|l|}{ After ETA } \\
\hline Main effects/adverse reactions related to ETA & 5 & 18,5 & 22 & 81,5 & 0 & 0 \\
\hline Main parameters that should be evaluated during and after ETA & 21 & 77,8 & 6 & 22,2 & 0 & 0 \\
\hline Routine hyperventilation as a way of preventing hypoxemia & 12 & 44,5 & 9 & 31,3 & 6 & 22,2 \\
\hline \multicolumn{7}{|l|}{ Practices for the prevention and control of infections } \\
\hline $\begin{array}{l}\text { Hand hygiene before and after ETA, as well as the use of gloves, } \\
\text { goggles and apron }\end{array}$ & 27 & 100 & 0 & 0 & 0 & 0 \\
\hline Permanence of sterility of the suction catheter & 25 & 92,6 & 2 & 7,4 & 0 & 0 \\
\hline Aspiration sequence (trachea, nose and lastly the oral cavity) & 22 & 81,5 & 5 & 18,5 & 0 & 0 \\
\hline Global average & 19,7 & 73,2 & 4,8 & 17,8 & 2,5 & 9 \\
\hline
\end{tabular}

* Endotracheal tube (orotracheal/nasotracheal tube and tracheostomy cannula)

Source: Research data.

Knowledge of professionals: according to the diagram score used in this study, the global knowledge of nurses was good (success rate of $85.3 \%)$; the nursing technicians it was average (success rate of $72.72 \%$ ) and; the nursing assistants' weak (success rate of $68.75 \%$ ). Globally, however, the professionals were qualified as average (73.2\% correct).

Proficiency of the professionals: 12 (44.5\%) expressed difficulties in at least one area of care that they provided to patients using an artificial airway. The most frequently mentioned area was the "cuff" pressure verification (11 times) followed by the insertion of the orotracheal tube (OTT), oral hygiene and positioning of the OTT, each was mentioned once. Twelve participants $(44.5 \%)$ reported that they had never received any in-service training on ETA.

\section{DISCUSSION}

A worrying result was observed when we discovered that in the following five areas: routine instillation of a physiological solution (PS) $0.9 \%$ in the TET; use of aspiration catheter of appropriate diameter; maximum time of aspiration with an open void; main adverse effects/ reactions related to ETA and; routine hyperventilation as a way of preventing hypoxemia, the knowledge of the professionals was classified as poor.

Considering that insufficient or incorrect knowledge leads individuals to inadequate 
practices, it appears that the lack of knowledge in these areas can cause complications such as hypoxemia, infections and hemodynamic instability and thus compromise patients' safety.

Informing patients in advance about the procedures that will be used and encouraging their participation, aside from being a human and ethical practice is also seen as an important strategy for reducing stress and anxiety, as well as maximizing the results of ETA ${ }^{(4)}$. In this research, $92.6 \%(n=25)$ of participants stated that it is necessary to explain the procedure to the patient, indicating very good knowledge on the subject. Similar results were found in a study conducted in Spain with ICU nurses, in which $100 \%(n=34)$ reported this practice and pointed out some aspects that should be addressed, such as what will be done and why, the sensations that can be felt and which concerns may be minimized with the administration of oxygen ${ }^{(4)}$.

The professionals were asked about the need to interrupt enteral feeding before starting the ETA. The success rate was $85.2 \%$, showing that they had good knowledge on the subject. This precaution is necessary as it helps to reduce VAP rates, since it helps to prevent vomiting and aspiration of that content through the lower airways $^{(7)}$.

The knowledge of the professionals on pre-oxygenation as a way of preventing hypoxemia was weak, as only $63 \%$ of respondents answered the question correctly. Despite the fact that the optimal technique (gold standard) for the provision of oxygenation in ETA (pre-oxygenation, post-oxygenation, insufflation and hyperinsufflation, alone or in combination) remains undetermined, the last AARC Guidelines ${ }^{(6)}$ recommend pre-oxygenation at $100 \%$ in pediatric and adult patients for 30 to 60 seconds (category 2B), especially in hypoxemic patients and in those whose oxygen saturation decreases during sucking. However, studies conducted with intensive care nurses showed that most of them know the importance of pre-oxygenation, but few use it routinely ${ }^{(4.5)}$.

Airway aspiration is required when there is a need to remove accumulated lung secretions. This can be evidenced by: 1) visible secretions in the airways; 2 ) the need to collect secretions for microbiological examination; 3) suspected aspiration of gastric fluid or upper airway; 4 ) the inability of patients to generate a spontaneous and effective cough; 5) a decrease in oxygen saturation and; 6 ) acute respiratory distress. The knowledge of the professionals in these areas proved to be very good, as $96.3 \%$, reported at least three of the six possible alternatives. The first four reasons for airway aspiration were identified in the majority of cases with 27, 25, 21 and 15 records respectively and the last two with 11 and 5 records respectively were less frequently mentioned.

Besides the above, there are other conditions that suggest ETA may be required, for example the presence of coarse crackles in the trachea, the standard "sawtooth" in the flow-volume circuit on the monitor screen of the fan and when the inspiratory pressure peak is increased during the volume control mode or decrease of the tidal volume during the controlled pressure ${ }^{(6)}$.

Regarding the time it takes to aspirate the airways, that is, routinely (pre-established hours as prescribed or unit routine) or only when necessary, the knowledge of participants was also viewed as very good as $926 \%$ correctly indicated that the ETA should be performed only when necessary. Despite this current recommendation, literature data shows that the procedure was traditionally performed routinely every one or two hours in order to prevent the occurrence of VAP and the occlusion of TET. However, over the course of years, several randomized studies indicated that there is no benefit in periodi- 
cally determined aspiration compared to that applied only when required. Furthermore, a higher number of aspirations put the patient at potential risk ${ }^{(9)}$.

When participants were asked about the routine instillation of PS $0.9 \%$ before the ETA, the knowledge of the professionals surveyed proved to be deficient, and was seen as poor, as only $44.5 \%$ correctly stated that it should not be applied routinely. Importantly, this procedure is the subject of much discussion, controversy and even conflicting results. The studies used in the preparation of the questionnaire were used as parameters to define what is correct or not.

The use of normal saline before ETA remained traditionally stable because it was believed that its use facilitated the removal of secretions by softening and thinning lung secretions, lubricating the suction catheter and stimulating coughing, which would facilitate the mobilization of secretions into the central airways, would increase the amount of secretions removed and would improve oxygenation. However, there is insufficient evidence to support this hypothesis, since a large number of studies registered insuficiency of $0.9 \%$ physiological saline to enhance the removal of secretions. Consequently, humidifying the inspired gas and hydrating patients systemically were more acceptable measures ${ }^{(11)}$.

Recent literature reviews found that, in recent years, different investigations have been conducted to determine the physiological and psychological effects of the instillation of such a solution in the ETA. Based on reports of post-extubation, gasometrical parameters, secretion removal, oxygen consumption and infection rates, the investigations included in the review showed that the procedure does not provide significant benefits. Instead, it is associated with discomfort and hemodynamic changes. In addition, this review provided evidence for asserting that the increased removal of secretions does not have clinical relevance as the amount of extra secretions removed ranged from one to two grams in the control group. Furthermore, the $0.9 \%$ physiological saline is quickly absorbed by the cardiopulmonary parenchyma and does not mix with the tracheobronchial secretions with only $18.7 \%$ of the instilled solution being recovered $^{(12)}$.

Faced with several controversies and no tangible benefits documented for the use of $0.9 \%$ physiological saline in the ETA, the AARC Guidelines $^{(6)}$ do not recommend its routine use (Category $2 \mathrm{C}$ ), since this procedure is associated with risks and complications and its use is allowed in the handling of secretions of difficult removal, as in the case of thick secretions and mucous plugs.

With regards to the size of the ideal aspiration catheter, the success rate was $59.2 \%$, indicating poor knowledge. This data is worrying because very large caliber catheters can cause considerable negative pressures to the airways, resulting, therefore, in a sudden drop in functional residual capacity, hypoxemia, atelectasis and traumas. Conversely, small caliber catheters do not provide satisfactory aspiration ${ }^{(13)}$.

Therefore, there is a consensus that the diameter of the catheter should be as small as possible, but large enough to facilitate the removal of secretions. Furthermore, in adults, the outer diameter of the suction catheter should occlude less than $50 \%$ of the internal diameter of the artificial airway. This allows ambient air to enter the lungs while the alveolar oxygen and other gases are being removed by the vacuum of the catheter ${ }^{(9)}$. Although much discussed, there is no evidence to support the exact ratio between suction catheter and TET. However, the following formula is widely recommended to calculate the ideal caliber of the aspiration catheter: aspiration catheter caliber $[\mathrm{Rf}]=(\mathrm{TET}$ Gauge $[\mathrm{mm}]-2) \times 2^{(13)}$. 
Worrying data was found that stated that the duration of the suction procedure (negative pressure established) is limited to a maximum of 30 seconds. The knowledge of participants on this subject was analyzed as poor, as only $33.3 \%$ answered the question correctly. In fact, based on clinical experiences and randomized studies, the current consensus recommended that the aspiration procedure should last no longer than 15 seconds. Excessive suction time can cause hypoxemia, atelectasis and respiratory distress ${ }^{(6)}$.

A considerable percentage of the professionals answered correctly when they said it is true that the patient should be monitored with pulse oximetry before, during and after the procedure (96.3\%) and the catheter should be inserted into the tube with the vacuum system shut $(92,6 \%)$. This knowledge was seen as very good in both areas. These practices were widely suggested and were emphasized by means of meta-analysis that aimed to clarify and analyze the effects of interventions implemented to prevent hypoxemia induced by ETA ${ }^{(14)}$.

Only $18.5 \%$ of respondents answered the question correctly regarding the main effects/ adverse reactions related to ETA. This result indicated poor knowledge and was at the same time alarming, considering that such professionals may underestimate the harmful effects arising from the procedure and, in practice, do not take the preventive measures recommended, which can result in mortality. The main effects/adverse reactions related to ETA include: increased blood pressure and intracranial pressure, hypoxemia, cardiac arrhythmias, cardiac and/or respiratory failure, bronchospasm, atelectasis, nosocomial infection, vagal overstimulation, damages the tracheobronchial tree, anxiety, bleeding, cardiovascular instability, neurological disorders and even death ${ }^{(8)}$.

With respect to the main parameters that should be evaluated during and after ETA, the success rate was $77.8 \%$, denoting average knowledge. The patient should be monitored regarding oxygen saturation, heart rate, level of consciousness, blood pressure and their reactions to the procedure ${ }^{(9)}$.

The professionals were informed that hyperventilation (increase in the amount of air that ventilates the lungs, either by increasing the respiratory rate or inspiratory flow) should not be routinely used. Only 12 (44.5\%) said that True was the correct answer, which was seen as poor knowledge. This result is disturbing, as this technique is not recommended as it can result in harmful effects, such as barotraumas and basic acids disorders ${ }^{(6)}$ and is also not supported from an ethical point of view. Recent statements from the Regional Council of Nursing of São Paulo concluded that "it is not the responsibility of the nurse to perform programming and parameter changes of Mechanic Pulmonary Ventilation devices"(15:3).

The professionals were asked whether the actions of hand hygiene (before and after the procedure), the use of gloves, goggles and apron were all necessary for the ETA. All (100\%) participants answered the question correctly and obtained the knowledge degree rated excellent. Hand hygiene is undoubtedly the most important measure in reducing the risk of transmission of microorganisms. It must be performed before and after the contact with patients, blood, body fluids, secretions, excretions and objects contaminated by such substances. However, the use of gloves, goggles and aprons is necessary in situations where blood or secretion splashing may occur ${ }^{(16)}$.

Regarding the permanence of sterility of the suction catheter, $92.6 \%$ of the professionals answered the question correctly, indicating very good knowledge on the subject.

In the literature, it is very well-known that the sterility of the catheter should be strictly maintained during all the steps of the ETA for open syste$\mathrm{ms}$, in addition to the aseptic measures ${ }^{(17)}$. Thus, targeting errors in this process and therefore the 
VAP, the enclosed aspiration system has emerged as an alternative to the open one. However, there is no literary consensus that the closed system reduces the incidence of VAP, given the controversial results found in several investigations ${ }^{(9)}$.

Well-designed and robust studies, with internal and external validity, are needed not only to affirm or refute the efficacy in preventing infections, but also to stratify from which final positive expiratory pressure (PEEP) this device is indicated to maintain the oxygen fraction and pulmonary pressures stable in patients who require high pressures. Confirmation is also required of the contribution of the closed system for occupational health and whether there is a reduction in the spread of microorganisms in patients with active tuberculosis when using this system ${ }^{(18)}$.

In airway aspiration, it is widely accepted that professionals should respect the sequence TET, nose, and finally, the oral cavity. $81.5 \%$ of the professionals answered the question relating to this area correctly, indicating good knowledge. This care is very important, since errors in this process may culminate in nosocomial infections $^{(1,3,4,9) \text {. }}$

The cuff pressure was the area of greatest difficulty reported by professionals in the management of artificial airways. This should be measured every eight to 12 hours, or whenever necessary, and should be maintained at between 15 and $25 \mathrm{mmHg}$ ( 20 and $34 \mathrm{cmH} 2 \mathrm{O}$ ). Higher values predispose to ischemic lesions and tracheal stenosis whereas lower values affect the mechanical ventilation and facilitate the aspiration of oropharyngeal secretions into the lower airways, increasing the risk of VAP ${ }^{(19)}$. Faced with such problems, it is up to the nurse not only to recommend and implement preventive protocols, but also the periodic evaluation of the adherence of the proposed measures; the application of clinical indicators and; continuing education ${ }^{(20)}$. Of equal importance is the commitment to quality and/ or improvement of structural and organizational issues, in addition to suitably qualified personnel and material resources.

The results of this study showed that the areas where knowledge was particularly poor related to the routine use of PS $0.9 \%$, suction catheter with proper diameter, maximum time of aspiration, main effects/adverse reactions related to the procedure and routine hyperventilation. Such results need to be analyzed and revised in teaching and nursing in the location of the research.

Limitations of this research include a lack of evaluation during periods of real assistance when professionals were carrying out an actual ETA procedure and their responses during this time, which restricted the development of this study; the sample was small, although it encompassed all the professionals in the units investigated. However, generalizations of the results are fragile.

\section{CONCLUSION}

The nursing professionals studied presented average knowledge about the ETA technique. In addition, the findings suggest that the greater the degree of professional instruction, the better the theoretical preparation for the procedure of ETA. Therefore, nurses had higher scores than nursing technicians who, in turn, exhibited higher scores than the nursing assistants.

The results suggest that there are some deficiencies in the knowledge of members of the nursing team. These results can guide the planning of strategies such as continuing education and adoption of preventative measures aimed at improving the level of knowledge of these professionals and, consequently, the quality of care provided. 


\section{REFERENCES}

1. Kelleher S, Andrews T. An observational study on the open-system endotracheal suctioning practices of critical care nurses. J Clin Nurs. 2008; 17 (3): 360-9.

2. Seckel MA. Does the use of a closed suction system help to prevent ventilator-associated pneumonia? Crit Care Nurse. 2008; 28 (1): 65-6.

3. Davies K, Monterosso L, Leslie G. Determining standard criteria for endotracheal suctioning in the paediatric intensive care patient: an exploratory study. Intensive Crit Care Nurs. 2011; 27 (2): 85-93.

4. Ania González N, Martínez Mingo A, Eseberri Sagardoy M, Margall Coscojuela MA, Asiain Erro MC. Assessment of practice competence and scientific knowledge of ICU nurses in the tracheal suctioning. Enferm Intensiva. 2004; 15(3):101-11.

5. Day T, lles N, Griffiths P. Effect of performance feedback on tracheal suctioning knowledge and skills: randomized controlled trial. J Adv Nurs. 2009; 65(7):1423-31.

6. American Association of Respiratory Care. AARC clinical practice guidelines: endotracheal suctioning of mechanically ventilated patients with artificial airways 2010. Respir Care. 2010; 55 (6): 758-64.

7. Celik SA, Kanan N. A current conflict: use of isotonic sodium chloride solution on endotracheal suctioning in critically iil patients. Dimens Crit Care Nurs. 2006; 25 (1):11-4.

8. Farias GM, Freitas MCS, Rocha KMM, Costa IKF.Pacientes sob ventilação mecânica: cuidados prestados durante a aspiração endotraqueal. Inter Science Place [Internet]. 2009Sep [cited 2012 Nov 25]; 2 (9): [about 5 p.]. Available From: http://www.interscienceplace. org/interscienceplace/article/view/109/111

9. Pedersen $C M$, Rosendahl-Nielsen $M$, Hjermind J, Egerod I. Endotracheal suctioning of the adult intubated patient - what is the evidence? Intensive Crit Care Nurs. 2009; 25 (1): 21-30.

10. Lourenço SA, Ohara CVS. Nurses' knowledge about the insertion procedure for peripherally inserted central catheters in newborns. Rev latinoam enferm. 2010; 18 (2):189-95.

11. Roberts FE. Consensus among physiotherapists in the United Kingdom on the use of normal saline instillation prior to endotracheal suction: a delphi study. Physiother Can. 2009; 61(2):107-15.
12. Halm MA, Krisko-Hagel K. Instilling normal saline with suctioning: beneficial technique or potentially harmful sacred cow? Am J Crit Care. 2008; 17 (5): 469-72.

13. Day $T$, Farnell $S$, Haynes $S$, Wainwright $S$, Wilson-Barnett J. Tracheal suctioning: an exploration of nurses' knowledge and competence in acute and high dependency ward areas. J Adv Nurs. 2002; 39 (1): 35-45.

14. Oh $\mathrm{H}$, Seo W. A meta-analysis of the effects of various interventions in preventing endotracheal suction-induced hypoxemia. J Clin Nurs. 2003; 12 (6): 912-24.

15. Conselho Regional de Enfermagem de São Paulo [homepage in the Internet]. Parecer n. ${ }^{\circ} 046$, de 06 de dezembro de 2010. Atribuições do enfermeiro e equipe de enfermagem na assistência ao paciente submetido à ventilação pulmonar mecânica [cited 2011 Sep 10]. Available From: http://portal.coren-sp.gov.br/sites/default/files/ parecer_coren_sp_2010_46_0.pdf

16. Freire ILS, Farias GM, Ramos CS. Prevenindo pneumonia nosocomial: cuidados da equipe de saúde ao paciente em ventilação mecânica invasiva. Rev eletrônica enferm. 2006; 8 (3):377-97.

17. Jongerden IP, Rovers MM, Grypdonck MH, Bonten MJ. Open and closed endotracheal suction systems in mechanically ventilated intensive care patients: a meta-analysis. Crit Care Med. 2007; 35 (1): 260-70.

18. Ferreira AOM, Silvino ZR, Christovam BP, Lima DVM. Aspiração endotraqueal em unidade de terapia intensiva: uma revisão integrativa. Rev enferm UFPE on line [Internet]. 2013;7(7):4910-7.

19. Jerre G, Silva TJ, Beraldo MA, Gastaldi A, Kondo C, Leme $F$, et al. Fisioterapia no paciente sob ventilação mecânica.J bras pneumol. 2007; 33 Suppl 2:142-50.

20. Silveira IR, Gnatta JR, Lacerda RA. Reproducibility and confiability of a processual indicator to evaluate adherence to oral hygiene in patients with orotracheal intubation. Online braz j nurs [Internet]. 2011 May [cited 2012 Nov 30]; 10(1): [about 6 p.]. Available From: http://www.objnursing.uff.br/index.php/nursing/article/view/3207

Received: 01/12/2012

Revised: $15 / 07 / 2013$

Aproved: 23/07/2013 